\title{
Multi-agent based Autonomous Power Distribution Network Restoration by using Contract Net Protocol
}

\author{
Junichi Kodama Student Member (Yokohama National University) \\ Tomoki Hamagami Member (Yokohama National University, hamagami@ynu.ac.jp) \\ Hiroshi Shinji Non-member (MEIDENSHA Corporation) \\ Takayuki Tanabe Non-member (MEIDENSHA Corporation) \\ Toshihisa Funabashi Member (MEIDENSHA Corporation) \\ Hironori Hirata Member (Chiba University, hiro@faclty.chiba-u.jp)
}

Keywords: multi-agent, power distribution network restoration, contract net protocol, genetic algorithm

A novel multi-agent-based system to achieve distributed approach for power distribution network restoration is proposed. In this system, if a fault occurs, agents assigned each section restore power distribution network condition autonomously and cooperatively by switching.

Complexity and diversity on the electric power system in Japan expect to increase because of development of distributed generation and new participants. In this trend, existing centralized control methods have limitation in terms of the scalability and robustness. In order to overcome the limitation, the distributed control approach has a potential to be breakthrough on the future issue.

Proposed method described in this paper is a effective distributed autonomous system for distribution network restoration instead of the legacy centralized control system. The proposed system consists of a number of agents interacting with each other. Each agent is assigned each area sectioned by switches, and monitor the condition of the section. If a fault occurs at an area of the network, the agent assigned the area begins to restore procedure to restore the network for reducing the influence of the trouble. In order to realize efficiencies of the procedure, the system applies the contract net protocol (CNP) by which agent exchanges information and act in concert with other agent (Figure 1).

This paper describes the two phases of the system, the evolutional phase for autonomous configuration and simulation experiment. First, parameters required to perform CNP effectively are optimized by the genetic algorithm. Then, if

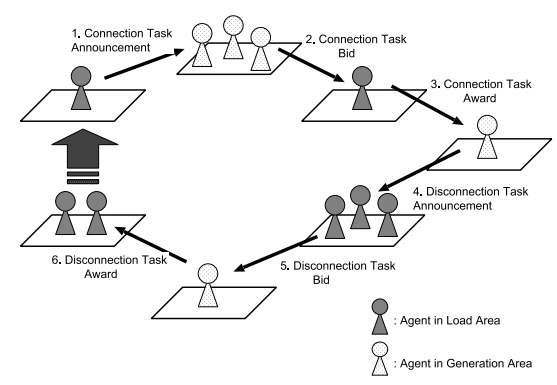

Fig. 1. Restoration process by using multiagent with CNP a fault occurs actually, appropriate and rapid procedures are realized by using these optimized parameters. In order to decide the agent actions through establishing the negotiation for restoring power distribution network, an agent executes and iterates three fundamental procedures task announcements, bids, and awards on the CNP. One action contracted by agents through CNP is the connecting for supplying the power, and another one is the islanding for trouble area. In order to realize suitable behavior of the network, properties of agent which decide priority among agents and dominate CNP condition need to be well-configured before in advance. Well configured parameters enable agents to have cooperative behavior. In this study, in order to configure the parameter, genetic algorithm (GA) is applied as autonomous approach. More specifically, with a parameter set is defined as a individual of GA, more appropriate parameter set is explored through simulation experiments. The results of simulation experiments (for example, Figure 2) show that the agents can perform properly for the power distribution network restoration by cooperating with other agents. Consequently, we confirm that the multi-agent-based distributed control approach contributes as a solution for the future power distribution network restoration.

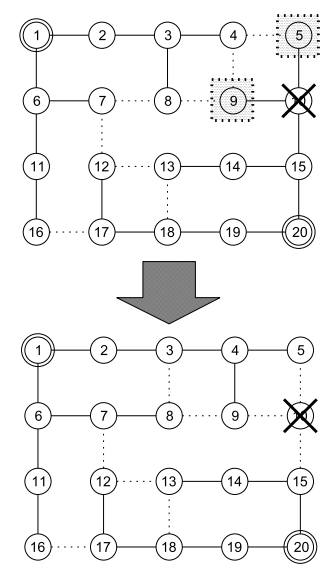

Fig. 2. The result of reconfiguration network in the simple model 


\title{
契約ネットプロトコルを用いたマルチエージェントによる 自律分散型の配電系統事故復旧方式
}

\author{
学生員 児玉 淳一* 正 員 濱上 知樹* \\ 非会員 宍道 洋** 非会員 田邊 隆之** \\ 正 員 舟橋 俊久** 正 員 平田 廣則 ${ }^{* * *}$
}

\author{
Multi-agent based Autonomous Power Distribution Network Restoration \\ by using Contract Net Protocol
}

Junichi Kodama*, Student Member, Tomoki Hamagami*, Member, Hiroshi Shinji**, Non-member,

Takayuki Tanabe**, Non-member, Toshihisa Funabashi**, Member, Hironori Hirata***, Member

\begin{abstract}
A nobel multi-agent-based system with the contract net protocol (CNP) for achieving distributed approach for power distribution network restoration is proposed. Agents in the proposed system are assigned to each area sectioned by switches, and exchange environmental information among them at all times. The information is used for constructing a overlay network of the CNP against network accidents. Parameters of CNP required for the robustness and effectiveness are optimized by the genetic algorithm (GA) in the operation phase. When a network accident occurs, the agents restore the power distribution service autonomously through the overlay network constructed by CNP. Simulation experiments indicate that the CNP allows the power distribution network to make effective strategy of the restoration by each agent cooperating.
\end{abstract}

キーワード：マルチエージェント, 配電系統事故復旧, 契約ネットプロトコル, 遺伝的アルゴリズム

Keywords: multi-agent, power distribution network restoration, contract net protocol, genetic algorithm

\section{1. はじめに}

近年，自然エネルギー発電や燃料電池発電をはじめとす る分散電源の技術が注目されている。環境負荷や発電コス 卜を低減できる分散電源は, 将来の新しい電力供給手段と して期待されている(1)。しかし，電力系統に分散電源が多 数導入されることにより，電力システムが多様化・複雑化 することが予想される。

一方, 従来の中央集中的な電力制御手法は, システムを作 るネットワークの構造・要素の情報が既知であることを前提

$*$ 横浜国立大学大学院工学府

干 240-8501 横浜市保土ケ谷区常盤台 79-5

Graduate School of Engineering, Yokohama National University

79-5, Tokiwadai, Hodogaya-ku, Yokohama 240-8501

** (株) 明電舎

₹ $103-8515$ 東京都中央区日本橋箱崎町 36-2

MEIDENSHA Corporation

36-2, Nihonbashi-Hakozakicho, Chuo-ku, Tokyo 103-8515

*** 千葉大学大学院自然科学研究科

263-8522 千葉市稲毛区弥生町 1-33

Graduate School of Science and Technology, Chiba University

1-33 Yayoi-cho, Inage-ku, Chiba 263-8522
としている。そのため, ネットワークの動的な変化に追従し て制御方法を変更することは極めて困難な問題である。

この問題に対し，近年，自律分散的なアプローチによる 新しい制御手法が提案されている。例えば，電力系統にお いての制御・運用に必要な様々な役割を持ったエージェン トから構成される自動システム(2)や, マルチエージェント を用いた事故診断手法 ${ }^{(3)}$ (4) など様々な分野における多数 の手法が提案されている。また，マルチエージェントベー スの手法により, 電力市場を分析するという研究も行われ ている(5) (6)。

これらのアプローチでは, ネットワーク上に分散された エージェントと呼ばれる主体が自律的に動作することで, 非 中央集中的な制御を実現している。しかし, 各エージェン 卜の役割や関連は予め設計された静的な情報をもとに決め られている。そのため, ネットワークの変更に対しては再 設計が必要になるという問題が残されていた。

以上のことを背景に, 本研究では, 配電系統の事故復旧 問題に着目し, マルチエージェント協調による新しい事故 復旧方式を検討している。マルチエージェントを用いた事 故復旧については，すでにいくつか研究が行われている(7) が, 系統構成が既知の固定環境を対象としたものであった。 
一方, 本研究においては, 分散電源の普及などによってエ ネルギー供給の地域性が高まったマイクログリッドのよう な環境を想定している。そのような環境においては，系統 の状態が時々刻々と変化する。

本研究の目的は, 系統全体のトポロジーや情報が分から なくても，局所的な情報を持つエージェントが協調的に動 作することによって, 系統全体として適切な処理を行うこ とができる自律分散協調型の配電系統事故復旧システムを 実現することである。これにより，系統の状態が変化した ときでも，それに対して柔軟かつ自律分散的に適応するこ とができる。具体的には，系統の動的な変化として，配電 ネットワークの構成状態の恋化や, 電源 ·負荷の追加, 削 除，容量変化を想定している。提案手法では，このように 系統全体の情報を常時集中的に把握していることが困難な 環境において，P2P 型の情報交換と契約ネットプロトコル $(\mathrm{CNP})^{(8)(9)}$ を用いたエージェント間の協調により配電系 統の事故復旧を行う。また，実際に事故が起きる前に，エー ジェント間の情報交換によって事故を想定したシミュレー ションを行い, 遺伝的アルゴリズム (GA) により CNPに 必要となるパラメータを最適化することで, 事故時の迅速 な処理を可能にする。

以下, 2 章では本研究で対象としている配電系統事故復 旧問題の概要について説明する。3 章では契約ネットプロ トコルを用いたエージェント間の協調によって事故復旧を 行う提案手法の詳細について述べる。 4 章では, 契約ネッ トプロトコルに必要なパラメータを遺伝的アルゴリズムに よって最適化する手法について述べる。5 章ではこれらの 提案手法の有効性をシミュレーション実験によって明らか にする。6 章はまとめである。

\section{2. 配電系統事故復旧問題}

本論文では，区分開閉器によって区切られた区間を“エ リア”と呼ぶ (図 1)。それぞれのエリアには電源と負荷が 含まれている。また，エリアを連結する開閉器は，電力だ けではなくエリア間のデータを中継する役割も持つものと する。本論文ではエリアと開閉器によって配電系統を模擬 する。

配電系統に事故が生じた場合には, 通常次の 3 ステップ の処理により復旧が行われる。

（1）事故点を特定して問題箇所を切り離す。

（2）開閉器を適切に切り替え, 停電エリアに他のエリ アから電力を融通する。

（3）事故点を修復後，系統を元の状態に戻す。

(1)の処理については，既にモバイルエージェントを用い た分散制御手法を提案している ${ }^{(10)}$ 。一方，(2)の処理では, できるだけ多くの負荷に電力が再供給されるように，効率 的に開閉器を操作する必要がある。その時, 以下の制約条 件が満たされていなくてはならない。

・電源容量制約：ある電源が電力を供給する負荷量の合 計は，その電源の容量を超えてはならない。

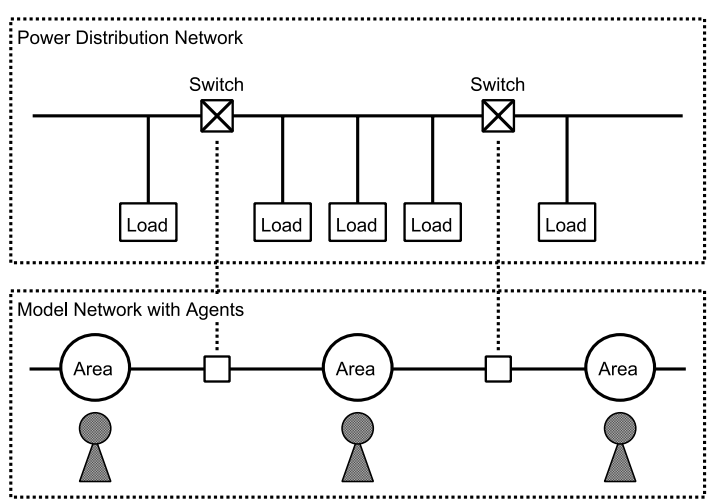

図 1 配電系統構成モデル

Fig. 1. The semantic model of a power distribution segment

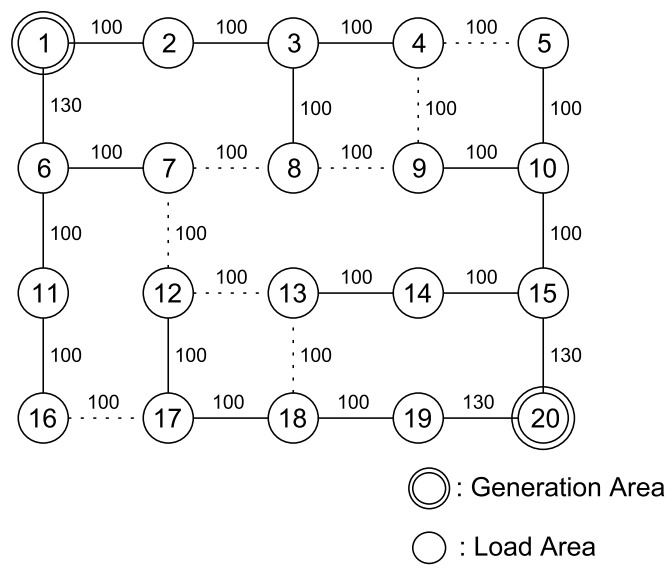

図 2 モデル系統例

Fig. 2. The example of power distribution network model

・線路容量制約：ある線路を流れる潮流量は，その線路 の容量を超えてはならない。

・放射状制約：構成される系統は放射状になっていなけ ればならない。

以上の制約の元で，開閉器の操作手順を決定する問題を, 配電系統の事故復旧問題と呼ぶ。以下, 図 2 のような網目 状の構成をした配電系統を想定した事故復旧問題の解法に ついて述べる。

\section{3. マルチェージェントによる事故復旧の概要}

本論文では，環境の状態を知覚し，自身の意思決定機構 に基づいて行動を行う自律的な主体をエージェント呼ぶ。 それぞれのエージェントは, 限られた情報と限られた範囲 への影響しか持たない。しかし, 複数のエージェントから 成るマルチエージェントの構成をとることで相互作用が発 生し, システム全体としての目的を達成するような協調的 動作を創発することができる。マルチエージェントによる 協調的動作を利用することで，系統全体の情報を一度に収 集することが困難な場合でも，適切な制御が可能となると 
期待できる。

〈3・1〉 エージェントの設定＼cjkstart各エリアごとにエリア 情報の管理や他のエージェントと通信を行うエージェント を配置する。エージェントは, 自エリアの発電量や負荷量, 線路容量, 開閉器の状態, 潮流量を保持している。また各 エージェントは，エージェント間の情報交換を中継し，そ の記録を管理する機能を持っている。

本手法では，これらの局所的な情報のみを持つエージェ ントが，以下で述べる契約ネットプロトコルによる交渉を 繰り返すことにより系統全体として適切な開閉器操作を実 行する。通常の系統運用中には, エージェントは他のエー ジェントと情報交換し，様々な事故を想定したシミュレー ションを繰り返しながら，CNPに必要なパラメータを最適 化する。そして実際に事故が起こったときには，そのパラ メータを用いて最適な復旧処理を行う。

〈3・2〉 契約ネットプロトコルを用いた復旧手順 CNP は，多数のエージェント間の交渉によって動的にタスクの 割り当てを行うためのモデルである。タスク告示，入札，落 札という基本的な交渉手順を行うことにより，タスクの割 り当てを行う。交渉を提案するエージェントをマネージヤ, 請負側エージェントを契約者と呼ぶ。それぞれのエージェ ントは状況に応じてマネージャにも契約者にもなりうる。

本手法では, 復旧過程に必要なタスクとして以下の 2 種 類を考える。

・連結タスク：停電エリアが他の経路からの電力融通を 受けるために連結を行うタスク。

・切り離しタスク：連結タスクを落札し実行する際に制 約違反が生じてしまう場合，それを解決するために負 荷の切り離しを行うタスク。

入札・落札の優先順位を決定する際に用いる評価基準と して以下の 2 種類を考える。

・復旧指数 $I_{a_{x}}\left(a_{y}\right)$ : あるエージェント $a_{x}$ の他のエージェ ント $a_{y}$ への復旧のしやすさを表す。この值が大きいほ ど $a_{y}$ へ電力を融通しやすいことを意味する。

・復旧指数 $J_{a_{x}}\left(a_{y}\right)$ ：あるエージェント $a_{x}$ の他のエー ジェント $a_{y}$ からの復旧されやすさを表す。この值が 大きいほど $a_{y}$ から電力を融通されやすいことを意味 する。

契約ネットプロトコルを用いたエージェント間協調によ る事故復旧手順の詳細を以下に示す (図 3)。エージェント はこれらの 7 ステップを繰り返すことにより復旧を行う。

（1）停電が生じた場合には, 停電エリアのエージェン ト $a_{x}$ はマネージャとして連結タスクの告示メッセー ジをブロードキャスト送信する。

（2）入札仕様を満たす発電エリアのエージェント $a_{y}$ は，契約者として入札の判断を行う。送信された告 示メッセージには有効期限があり, 満期を迎えたメッ セージから順次入札の判断をする。このとき, 現在 保持している他のタスク告示メッセージの優先度と 比較し，その中で最も優先度が高い場合に，入札メッ

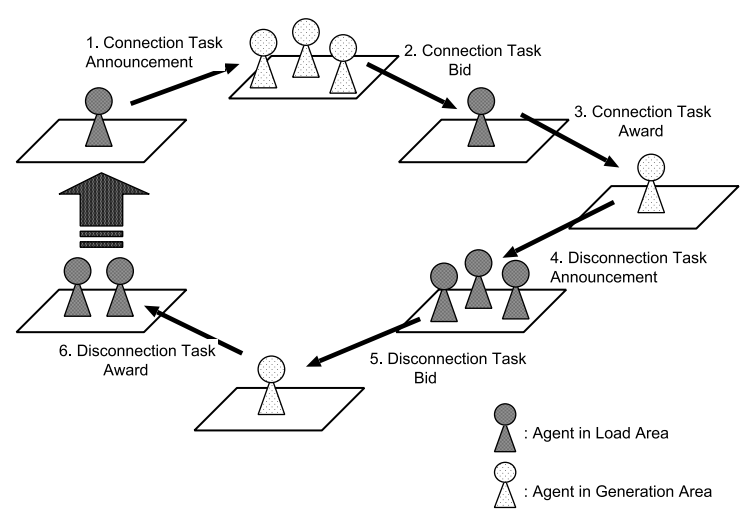

図 3 契約ネットプロトコルによる事故復旧手順

Fig. 3. Restoration process using CNP

セージを送信する。入札メッセージには，タスク告 示エージェントへの復旧しやすさの指標 $I_{a_{y}}\left(a_{x}\right)$ が 含まれる。

（3）入札メッセージを受け取ったマネージャ $a_{x}$ は，落 札エージェントを決定しメッセージを送信する。落 札エージェントを決定する際の優先順位は, 入札メッ セージに含まれている $I_{a_{y}}\left(a_{x}\right)$ に基づいて決定する。 $I_{a_{y}}\left(a_{x}\right)$ は自エリアへのそのエリアからの電力融通 されやすさを表しているため, その值が大きいほど 落札優先順位も高くなる。

（4）落札メッセージを受け取ったエージェントは，連 結タスクを実行するために開閉器の操作を行う。こ のとき, 電力融通経路中のエリアのエージェントに 対しても開閉器操作の指令を送信する。その夕スク 実行によって制約違反が生じる場合は，タスクを実 行する前に切り離しタスクの告示を行う。

（5） 入札仕様を満たす負荷エリアのエージェント $a_{z}$ は 入札を行う。入札メッセージには, 当該エリアの復 旧されやすさの指標の最大值 $J_{a_{z}}\left(a_{q}\right)$ が含まれる。

（6）入札メッセージを受け取ったマネージャは，落札 エージェントを決定し, 落札メッセージを送信する。 落札エージェントを決定する際の優先順位は, 入札 メッセージに含まれている $J_{a_{z}}\left(a_{q}\right)$ に基づいて決定 する。 $J_{a_{z}}\left(a_{q}\right)$ はそのエリアの電力融通されやすさ を表しているため, その值が大きいほど, 切り離し を行った際に他の経路から電力を受けやすいことを 意味する。そのため, 落札優先順位も高くなる。制 約違反の状況に応じて, 契約者は複数になることも ある。

（7）落札メッセージを受け取ったエージェントは，夕 スクを実行するために開閉器の操作を行う。そして 他からの電力融通を受けるため, 連結メッセージの 告示を行う。

\section{4. 遺伝的アルゴリズムを用いた評価指数の最適化}

以上で述べた $I_{a_{x}}\left(a_{y}\right), J_{a_{x}}\left(a_{y}\right)$ によって作られるエー 
ジェント間の依存関係は, 物理的な配電系統ネットワーク 上につくられた電力融通のためのオーバレイネットワーク となる。システム全体が適切に機能するためには, エージェ ント同士が協調的に動作するようなネットワークを構成し ておく必要がある。本研究では，ネットワークを構成する $I_{a_{x}}\left(a_{y}\right), J_{a_{x}}\left(a_{y}\right)$ の集合を見つける問題を, 組み合わせ最 適問題とみなす。そして，その探索手法として GA を用 いる。

また，実際に事故が起きたときに迅速かつ適切な復旧を 行うためには，通常の運用中にその時の系統状態に合わせ てこれらのパラメータを最適化させておくことが望ましい。 そこで本手法では，エージェント間の $\mathrm{P} 2 \mathrm{P}$ 型情報交換を用 いた事故を想定したシミュレーションによって，実際に事 故が起きる前に適切な復旧指数 $I_{a_{x}}\left(a_{y}\right), J_{a_{x}}\left(a_{y}\right)$ の集合を エージェントに獲得させておく。

$\langle\mathbf{4} \cdot \mathbf{1}\rangle$ 遺伝子表現 本手法では, 1 つの $I_{a_{x}}\left(a_{y}\right)$, $J_{a_{x}}\left(a_{y}\right)$ 集合で表されるオーバレイネットワークを 1 個体で 表現し，個体集合の進化の中から，適切なオーバレイネッ トワークを探索する。ここで，探索範囲を狭めるために， 復旧のされやすさ $J_{a_{x}}\left(a_{y}\right)$ は, 相手に依存しないと仮定し, $J_{a_{x}}\left(a_{y}\right)=J_{a_{x}}$ と表す。

個体の遺伝子型の設定は以下のように行う。

・系統全体のエージェントがそれぞれ保持する復旧指数 の集合を一個体とする。

・それぞれのエージェントが保持する復旧指数の実数值 列を遺伝子とする。

$\langle\mathbf{4} \cdot \mathbf{2}\rangle$ 適応度算出方法 系統中の任意のエリアで事 故が起こったと仮定したシミュレーションを行い，〈3.2〉で 記述した手順に従って CNPによる仮想の復旧動作を実行 する。復旧処理が終了した後で, 停電負荷の復旧状況を計 算し，これを適応度とみなす。この際，事故が起きた系統 の状態・復旧処理が行われた系統の状態は，エージェント 間の情報交換によってシミュレーション計算される。

〈4・3〉 評価指数獲得の手順 GAによる復旧指数の獲 得は，図 4 に示されるような以下のアルゴリズムによって 行われる。

（1）ランダムな值を遺伝子とした個体を初期集団とし て $N_{\mathrm{i}}$ 個生成する。

（2）それぞれの個体について，遺伝子情報を対応する エージェントに与え，〈4.2〉で記述した方法によって 適応度を計算する。

（3）適応度の高い上位半数の個体を次世代の親として 選択する。

（4）子の原型として親のコピーを行う。

（5）4で生成された個体に対して 1 点交叉を行い新た な個体 (子) を作る。

（6）さらに5で生成された個体に対して突然変異を行 い，新たな個体を作る。突然変異は，個体中の任意 の復旧指数一つをランダムな值に書き換えることに よって行う。

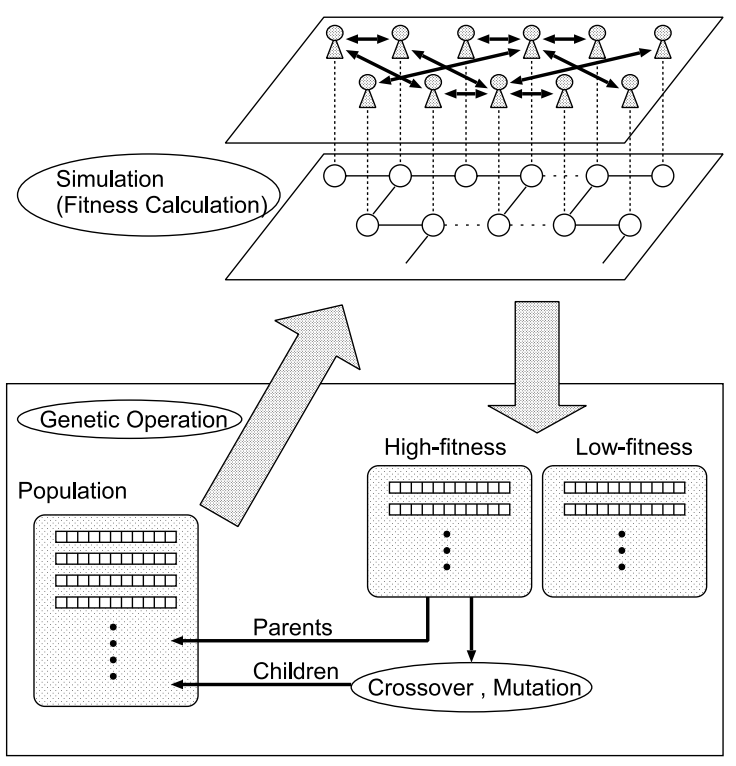

図 4 GA による復旧指数獲得の概要

Fig. 4. Optimization process using GA

（7）生成された親と子を個体集団として，設定された 世代数だけ $2 \sim 6$ を繰り返す。

本論文においては，上記の最適化過程における交叉・突 然変異 - 選択といった遺伝的操作は, 中央集中的に行って いる。しかし，個体評価 (適応度計算) の際のシミュレー ションは，エリアに配置されたエージェント隣接間の情報 交換によって行うことができる。よって，遺伝的操作を行 う中央の計算機は個体の遺伝子情報 (各エージェントの復 旧指数) だけを保持していればよく，トポロジーやエリア 情報など系統の状態について把握している必要はない。

\section{5. シミュレーション実験}

〈5・1〉簡易モデルによる復旧実験 図 2 に示した簡 易な配電系統モデルに対し, 提案手法による事故復旧問題 の解決を図った。実験モデルにおいて，エリア 1 と 20 は電 源容量 250 の発電エリア, 他は負荷量 20 の負荷エリアと した。また，実線のリンクは開閉器が閉じている状態，破 線のリンクは開閉器が開いている状態，リンクの上の数值 は線路容量を表している。

このモデル系統において，GAによる復旧指数の最適化 を行った。GAにおけるエージェント数 $N_{\mathrm{a}}$, 個体数 $N_{\mathrm{i}}$, 交 叉率 $P_{\mathrm{C}}$ ，突然変異率 $P_{\mathrm{m}}$ の設定を表 1 に示す。

1 世代中でランダムに 3 箇所の事故を起こし復旧動作を 行う。図 5 に，各世代ごとの個体平均の未復旧負荷量の変 化を示す。実験の結果，およそ0～50 世代にかけて未復旧 負荷量の平均值が漸進的に減少し，適切なオーバレイネッ トワークが構成されていく様子が確認できた。

次に，200世代後のエリート個体の中で，最も適応度の 高い個体を用いて復旧動作を行った。例として，エリア 10 に事故が起きたときの復旧結果を図 6 に示す。エリア 10 の 事故により，エリア $5 ， 9$ が停電する。その後，エリア 5 , 
表 1 GA におけるパラメータ

Table 1. The parameter of GA

\begin{tabular}{cccc}
\hline$N_{a}$ & $N_{i}$ & $P_{c}$ & $P_{m}$ \\
20 & 200 & 0.5 & 0.1 \\
\hline
\end{tabular}

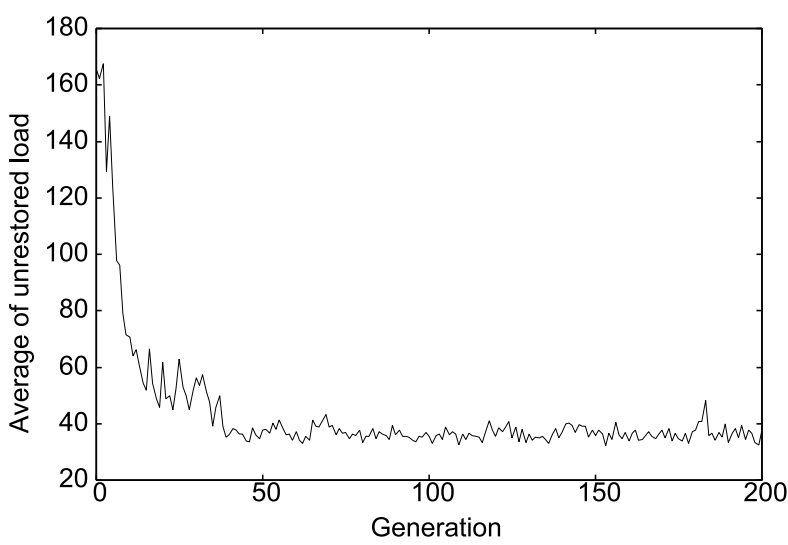

図 5 世代ごとの未復旧負荷量平均值の変化

Fig. 5. Change of the average of unrestoration load against generations in the simple distribution model

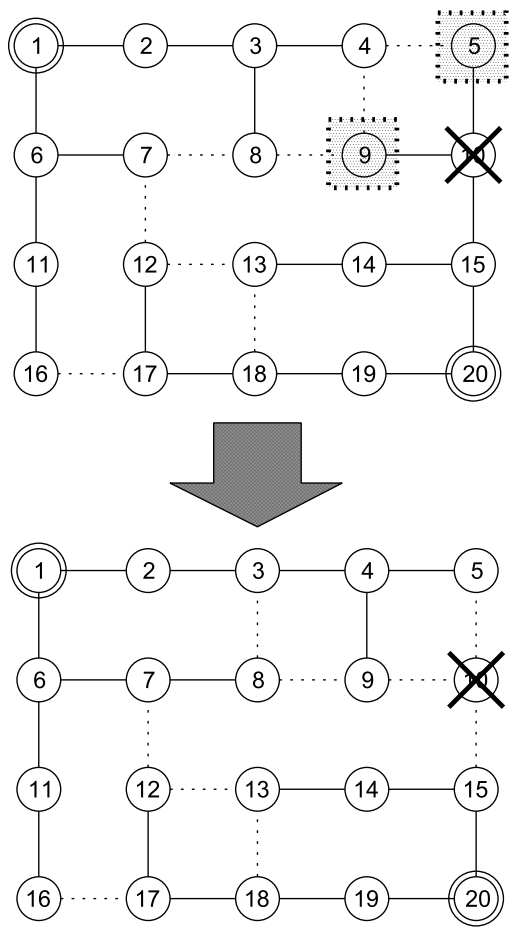

図 6 復旧後の配電系統

Fig. 6. The result of reconfiguration network in the simple model

9 からの連結夕スクが発生し，いくつかの処理を経てエリ ア 4 に連結し，エリア 8 がエリア 3 からエリア 7 に連結の 切り替えをすることによって，停電エリアが復旧されてい た。また，他の事故ケースにおいても，各エージェントが 協調的に動作し，系統全体として適切な復旧が行われるこ とが確認された。

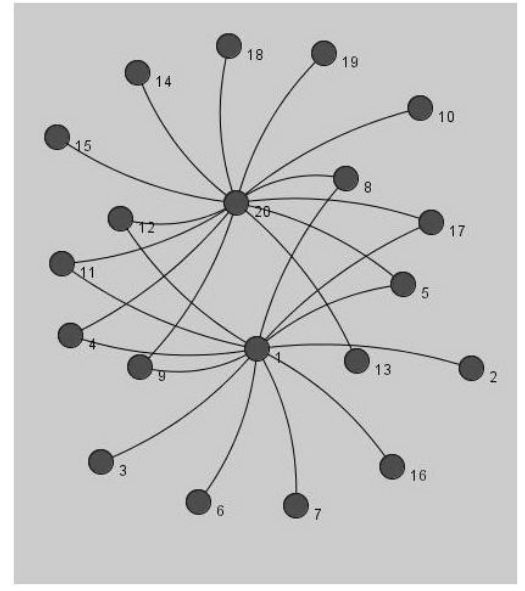

図 7 構築されたオーバレイネットワーク

Fig. 7. The result of the constructed overlay network in the simple model

提案手法によって構成されたオーバレイネットワークを 図 7 に示す。図 7 は, 復旧動作の際の CNP を用いた交渉 過程において生じた入札・落札の関係を，エージェント間 のリンクとして表したものである。図 7 を見ると，電源 であるエリア 1 とエリア 20 がネットワークにおいてハブ のような役割を持っていることが分かる。さらに，エリア 4,5,8,9,11,12,17 がエリア 1,20 を中心とする 2 つのサブネッ トワークをつなぐ役割を担っている。これらの役割は，局 所的な情報しか持たないエージェント間の交渉過程の中か ら自律的に生じた構造であり, 系統全体の情報が既知でな い環境に挸いても，マルチエージェントによる協調動作に より復旧のための関係構築が実現できたといえる。

$\langle\mathbf{5} \cdot \mathbf{2}\rangle$ 実規模配電系統モデルを用いた復旧実験 本 手法が実規模の配電系統に対しても有効であるかどうかを 確認するために，奈良らが文献 (11) で用いた実規模配電系 統モデルを用いた実験を行った。眓 8 に，用いた実規模配 電系統モデルの構造および負荷を示す。実験条件は簡易モ デルの場合と同様とした。

図 9 に，世代毎のエリートおよび集団平均の未復旧負荷 量の変化を示す。事故直後の未復旧負荷量の平均が 1287.3 であるのに対し，最適化を行うことで，世代を追うごとに 未復旧負荷量が減少し, 未復旧負荷量は 427.6 まで減少す ることが確かめられた。

図 10 に，本実験で作られたオーバレイネットワークを 示す。簡易モデルの場合と同様に，発電エリアに相当する 4 つのエリア $(1,27,40,56)$ がハブとなり，4つのスター型 ネットワークを構成していることがわかる。さらにこれら のネットワークがリンク数 2 または 3 の連結エリアによっ て，相互にネットワークを構成していることがわかる。

図 11 に,リンク数毎のエリア数（エージェント数）の 頻度を両対数軸上にプロットした結果を示す。得られた線 はほぼ右下がりの直線になっている。このような特徵から， 本手法により構成されたオーバレイネットワークは，自然 

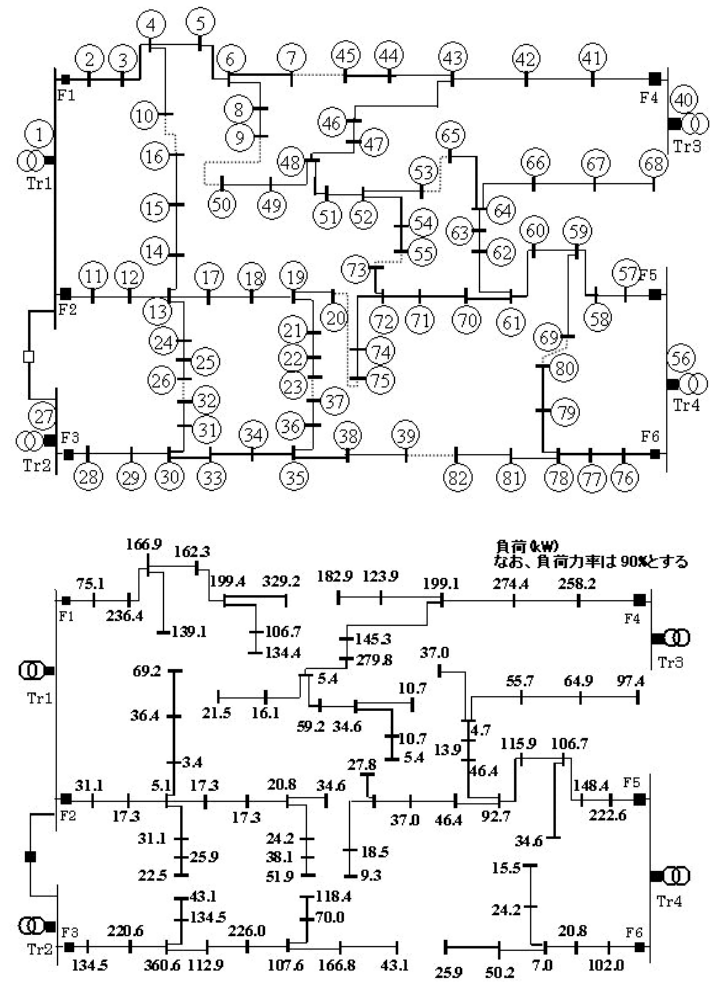

図 8 実規模配電系統図 (文献 (11))

Fig. 8. A real scaled distribution network model

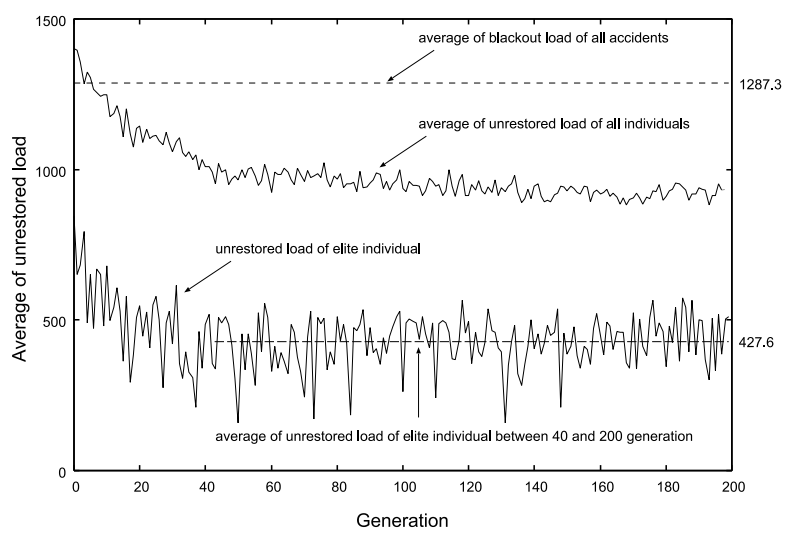

図 9 実規模配電系統における世代毎の復旧負荷 量の変化

Fig. 9. Change of the average of unrestoration load against generations in the real scaled distribution model

界によくみられるスケールフリーの構造に近いことがわか る。一般にスケールフリーネットワークは，任意点におけ る故障に対するロバスト性が高いことが知られている。マ ルチエージェント間の協調動作により，このようなオーバ レイネットワークが構成されたことで，任意点での事故復 旧問題に対して，系統の物理的構造を反映した頑健なエー ジェント間の関係性が獲得できたと結論付けられる。

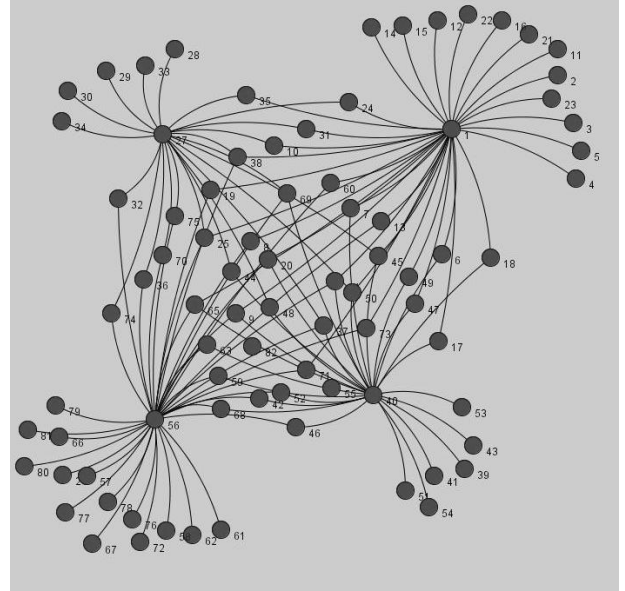

図 10 実規模配電系統上に構築されたオーバレ イネットワーク

Fig. 10. The result of the constructed overlay network in the real scaled model

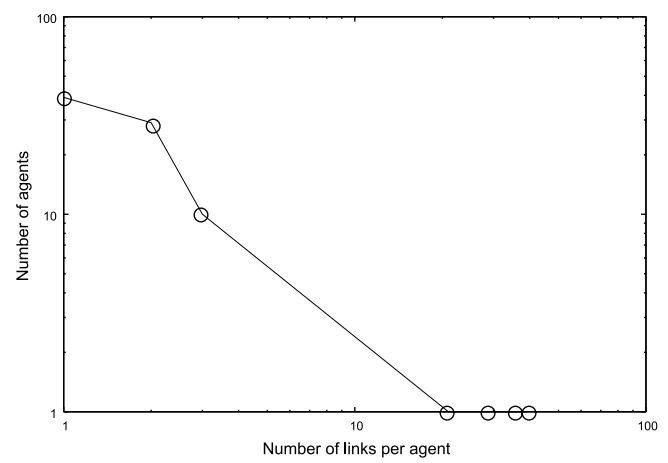

図 11 実規模配電系統上オーバレイネットワー クにおけるリンク数とエリアの数の関係

Fig. 11. The number of areas (agents) against the number of links with the areas (agents)

\section{6. おわりに}

配電系統の事故復旧において，CNP を用いたエージェン 卜間の協調による手法を検討した。また，事故を想定した シミュレーションを行い，GAによって CNP に必要なパ ラメータをあらかじめ獲得させておくことで, 実際に事故 が起きたときに適切な復旧動作を行えることを確認した。 本手法により, 配電系統という物理的なネットワーク上に, CNP によるエージェント間の相互依存性に基づいたオー バーレイネットワークが構成され，適切な復旧処理が行え ることが確認された。

今後は，構成されたオーバレイネットワークの解析を基 にエージェントの関倸性についての考察を深めるとともに, 配電系統の分析・評価ツールとしての本手法の有効性につ いて検討する予定である。また, 本論文においては最適化 に打ける遺伝的操作を中央集中的に行っているが，これを 分散的に行うことによって, より実環境に適したシステム として発展させていく予定である。

(平成 18 年 5 月 9 日受付, 平成 18 年 9 月 5 日再受付) 


\section{文献}

（1）SMART 研究会：「地域分散エネルギー技術」，海文堂（2004）

(2) C. Rehtanz: "Autonomous System and Intelligent Agents in Power System Control and Operation", Springer(2003)

(3) J. Yang, M. Montakhab, A.G. Pipe, B. Carse, and T.S. Davies: "Application of Multi-Agent Technology to Fault Diagnosis of Power Distribution Systems", Proceedings of Engineering of Intelligent Systems, February 29 - March2 (2004) Island of Madeira, Portugal

(4) S.D.J. McArthur, E.M. Davidson, J.A. Hossack, and J.R. McDonald: "Automating Power System Fault Diagnosis through Multi-agent System Technology", Proc. 37th Hawaii Inter. Conf. System Sciences (2004)

(5) T. Hamagami: "Using Intelligent System Approaches for Simulation of Electricity Markets", IEEJ Trans. EIS, Vol.126, No.2, pp.156-160 (2006-2) (in Japanese) 濱上知樹：「知的情報処理を用いた電力市場のシミュレーション」, 電学論 C, 126, 2, pp.119-124 (2006-2)

(6) A. Rahimi-Kian, B. Sadeghi, and R.J. Thomas: "Q-Learning Based Supplier-Agents for Electricity Markets", IEEE Power Engineering Society General Meeting (2005)

(7) T. Nagata, H. Sasaki: "A Multi-Agent Approach to Power System Restoration", IEEE Trans. on Power Syst., Vol.17, No.2, pp.457-462 (2002)

(8) R. Davis and R.G. Smith: "Negotiation as a Metaphor for Distributed Problem Solving", Artificial Intelligence, Vol.20, No.1, pp.63-109 (1983)

(9) R.G. Smith: "The contract net protocol: High-level communication and control in a distributed problem solver", IEEE Trans. on Comput., C-29, pp.1104-1113 (1980)

(10) H. Shinji, T. Tanabe, Y. Matsuura, Y. Okuno, and T. Funabashi: "Control of Distribution System with Distributed Generations using Mobile Agent", Proc. of the 2004 Joint Conf. of IEEJ and IEICE pp.119-124 (2004) (in Japanese) 宍道 洋 - 田邊隆之・松浦嘉宏・奥野義道・舟橋俊久：「モバイル エージェントによる分散電源系統制御」, 平 16 電学・信学合同講演 会論文集，pp.119-124 (2004)

（11）青木兼一・奈良宏一・佐藤泰司：「復旧の優先順位を考慮した配電 系統の事故時負荷切換」, 電学論 B, Vol.110, No.9, pp.710-718 (1990-9)

（12）肾玉淳一・宍道 洋・田邊隆之・濱上知樹：「マルチエージェント による分散協調型の配電系統事故復旧方式」, 平 18 電学全大講演論 文集，Vol.7，pp.172-173 (2006)

(13) J. Kodama, H. Shinji, T. Tanabe, T. Funabashi, and T. Hamagami: "Autonomous Power Distribution Nwtwork Restoratoration Strategy by Using Multi-agent and the Contract Net Protocol", Inter. Conf. Elec. Engineer. 2006 (ICEE2006)

濱 上 知 樹

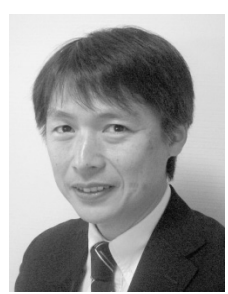

(正員) 1966 年 3 月 7 日生。 88 年千葉大学工学 部電気工学科卒業。セコム (株) 勤務を経て, 99 年在職のまま千葉大学大学院自然科学研究科生産 科学専攻後期課程修了。2001 年同助手。2004 年 横浜国立大学大学院工学研究院助教授。分散知能 システム, マルチエージェント, 強化学習, 福祉・ 医療支援等社会システムへの応用研究に従事。博 士 (工学)。IEEE，電子情報通信学会，情報処理

学会各会員。

宾 道

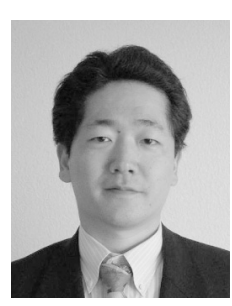

田 邊 隆 之 (非会員) 1969 年 9 月 19 日生。1994 年山梨大

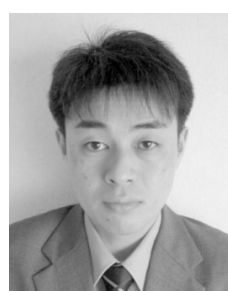

舟 橋 俊 久 (正員) 1951 年 3 月 25 日生。1975 年名古屋大

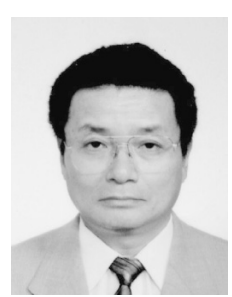
学工学部電気工学科卒業。同年 4 月 (株) 明電舎入 社。主として電力系統解析業務に従事。博士（工 学), C. Eng. (英国技術士)。IET 会員, IEEE シ ニア会員。 学大学院工学研究科機械システム工学専攻修了。 同年 4 月 (株) 明電舍入社。電力系統解析業務，分 散型電源の系統連系技術等の業務に従事。日本機 械学会, 計測自動制御学会各会員。
児 玉 淳 - (学生員) 1983 年 2 月 4 日生。 2005 年横浜国立

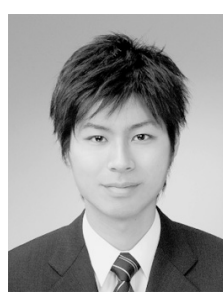
大学工学部電子情報工学科卒業。同年横浜国立大 学大学院工学府物理情報工学専攻博士前期課程入 学, 現在在学中。マルチエージェントを用いた電 カシステムに関する研究に従事。
平 田 廣 則 (正員) 1948 年 6 月 2 日生。 76 年東京工業大学大

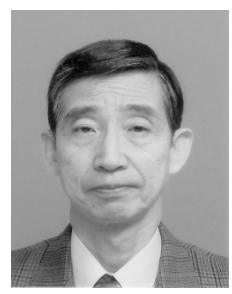
学院電気工学専攻博士課程修了。同年千葉大学工 学部助手， 81 年同助教授，94 年同教授，97 年同 大学院自然科学研究科教授となり現在に至る。大 規模システムのモデリング，解析と設計，特に生態 システム, VLSI レイアウト, 並びに分散システム の基礎的理論に興味を持つ。工学博士。2001 年電 気学会業績賞受賞, IEEE Fellow。IEEE, INNS, 電子情報通信学会, 情報処理学会, 計測自動制御学会, システム制御 情報学会, 人工知能学会各会員。 